\title{
What Are the Determinants of Insulin Resistance (IR) and How Effective Is the Sub-Saharan Africa-Specific Threshold of Abdominal Obesity (AO-SSA) Identifying IR in Congolese Black Hypertensive Patients?
}

\author{
Bernard Kianu Phanzu1*, Benjamin Longo-Mbenza², Jean Bosco Kasiam Lasion'kin ${ }^{3}$, Jody \\ Mbuilu Pukuta4 ${ }^{4}$ Eleuthère Kintoki Vita1, Nanoue Masolo Muze Kianu ${ }^{5}$ \\ ${ }^{1}$ Department of Internal Medicine, Unit of Cardiology, University of Kinshasa Hospital, Kinshasa, Democratic \\ Republic of Congo \\ ${ }^{2}$ Faculty of Health Sciences, Walter Sisulu University, Mthatha, South Africa \\ ${ }^{3}$ Department of Internal Medicine, Unit of Endocrinology and Metabolism, University of Kinshasa Hospital, \\ Kinshasa, Democratic Republic of Congo \\ ${ }^{4}$ Department of Family Medicine, University of Witwatersrand, Johannesburg, South Africa \\ ${ }^{5}$ Faculty of Medicine, University of Technology, Bel Campus, Kinshasa, Democratic Republic of Congo \\ Email: doctorkianu@gmail.com
}

Received 28 September 2014; revised 16 November 2014; accepted 30 November 2014

Copyright (C) 2014 by authors and Scientific Research Publishing Inc.

This work is licensed under the Creative Commons Attribution International License (CC BY). http://creativecommons.org/licenses/by/4.0/

(c) () Op Open Access

\section{Abstract}

Background: Hypertensive patients with insulin resistance (IR) are at greater risk of cardiovascular disease and may represent a particular subset of hypertension (HTN) requiring special medical attention. Quantitative measurements of the IR are not suitable for routine clinical practice. Metabolic syndrome (MetS) or simply abdominal obesity (A0) is surrogate of IR. The performance of the recently proposed Sub-Saharan Africa cut-off point of abdominal obesity for identifying IR in hypertensive patients has never been evaluated. Aims: The main objective was to compare the performance of the newly proposed Sub-Saharan Africa specific threshold of abdominal obesity (AO-SSA) to that of IDF (AO-IDF) in identifying IR in Congolese Black Hypertensive Patients. Methods: A cross-sectional study was conducted at the Heart of Africa Cardiovascular Center, Lomo Medical Clinic, Kinshasa Limete, DR Congo, between January 2007 and January 2010. Homeostatic model assessment (HOMA) index was calculated to determine IR. Multivariate logistic regression analysis was used to assess the independent determinants of IR. The intrinsic (sensitivity and spe-

\footnotetext{
"Corresponding author.
} 
cificity) and extrinsic (positive predictive value and negative predictive value) characteristics of the AO-SSA, AO-IDF, AO-ATP III, MetS-SSA, MetS-IDF, and MetS-ATP III were calculated. The kappa statistic was determined for agreement between the ATPIII, IDF and SSA defined AO and MetS with HOMA-IR. Results: Men represented the majority of the enrolled patients: $105(64.4 \%)$ and the mean age of all participants were $57 \pm 11$ years. Insulin resistance was found in $79.1 \%$ of the study population with $88.7,79.3,84.6,71.4,75.5,91.1,60.3$ and 44.8 respectively among patient with MetS-ATP, MetS-IDF, MetS-SSA, A0-ATP III, AO-IDF, AO-SSA, diabetics and non-obese non-diabetic hypertensive patients. In multivariate analysis, the risk of IR was associated independently and significantly $(p<0.05)$ with cigarette smoking, low-HDL-C, hyperuricemia, and diastolic HTN, as shown in the following equation: $\mathrm{Y}=\mathbf{- 1 . 4 0 4}+\mathbf{1 . 0 5 4}$ Cigarette Smoking $+\mathbf{0 . 8 7 2}$ low HDL-C +0.983 hyperuricemia + 0.852 diastolic hypertension. The AO-SSA, with $87.7 \%$ sensitivity and $67.6 \%$ specificity, was the only surrogate who showed an acceptable agreement with the HOMA-IR index. Abdominal obesity defined according to other thresholds and the metabolic syndrome whatever the used diagnostic criteria have a slight agreement with the HOMA-IR index. Conclusion: IR was found to be prevalent in our study population. Cigarette smoking, low-HDL-C, hyperuricemia, and isolated diastolic HTN magnify IR. The AO-SSA is an easy and cost efficient method to diagnose IR in Congolese Black Hypertensive Patients. Further study in wider group is indicated to validate our findings.

\section{Keywords}

\section{Insulin Resistance, Hypertension, Sub-Saharan Africa, Abdominal Obesity}

\section{Introduction}

Hypertension (HTN) is a major public health problem, responsible for disability and mortality [1]-[4]. It affects nearly a quarter of the world's adult population [5], and is the most common condition seen in primary care [6]. In Sub-Saharan Africa (SSA), HTN is the most prevalent and the most threatening cardiovascular risk factor [7]-[9], experiencing a dramatic growth, affecting younger people, with poorer blood pressure control, and singularly moving early to cardiovascular complications [10]-[12]. In this part of the globe, more than 500 million new cases are expected in 2025 versus 70 million in Western countries [13]. That's why, in the 2014 World Congress of Cardiology held in Melbourne, hypertension has been called the scourge of the African continent. In the Democratic Republic of Congo (DRC), the prevalence of HTN increased from 5\% in 1986 to 30\% in 2006 and 2007 in some population based studies [14]-[16]. Nowadays, seven years after these studies, a higher prevalence is more than plausible hypothesis because since then there has been no real riposte to counter this threatening scourge. Insulin resistance (IR) is a state of reduced insulin target cells responsiveness to normal or elevated circulating levels of insulin [17]-[19]. It is an independent risk factor for cardiovascular disease [18]-[20]. Insulin resistance (IR) and compensatory hyperinsulinaemia commonly occur in patients with essential HTN [21]-[24] and it represents a major underlying abnormality driving cardiovascular disease [25]-[36]. Thus, hypertensive patients with insulin resistance are at greater risk of cardiovascular disease and may represent a particular subset of HTN requiring special medical attention [20] [37]-[40]. Quantitative measurements of the IR, including glucose clamp methods and insulin suppression test, are not used in daily clinical practice. Indeed they are labor-intensive, time-consuming, expensive, and technically challenging [41] [42]. A number of surrogate indices have therefore been employed to simplify and improve the determination of insulin resistance [42] [43]. Thus, it is generally considered that subjects with metabolic syndrome (MetS) or abdominal obesity (AO) are carrying IR [44]-[47]. In this context, and given that there are several definitions of metabolic syndrome and multiple thresholds used to define abdominal obesity, the choice should focus on the one with the best performance for identifying insulin resistance. IDF have proposed a worldwide definition with waist circumference cut-points that are gender and ethnic-group specific [48]. For Sub-Saharan African it has been recommended to use European cut-off of $\geq 94 \mathrm{~cm}$ for male and $\geq 80 \mathrm{~cm}$ for female until more specific data could be available [48]. Provisional thresholds have also been proposed for other ethnic groups, most of which have since set their own thresholds [49]-[51]. In DRC, Kasiam et al. have set the WC threshold at $94 \mathrm{~cm}$ regardless of gender, from a population based study [47] [52]. Is 
this threshold better, i.e. more efficient in identifying insulin resistance than the IDF that was offered to be use temporarily?

The aim of this study was to compare the performance of the Kasiam et al. proposed Sub-Saharan Africaspecific thresholds of abdominal obesity (AO-SSA) to that of IDF in identifying IR in the study population. Moreover, we determined the prevalence and identified the independent determinants of insulin resistance in the study population.

\section{Patients and Methods}

\subsection{Study Population}

This is a cross-sectional study that was held from 5 January 2007 to 5 January 2010 at Lomo Medical Clinic, Kinshasa, megacity and capital of the Democratic Republic of the Congo (DRC).

The target population consists of hypertensive patients been followed in the Lomo Medical Center for essential HTN. To be eligible for this study, the patients should be black Congolese $\geq 18$ years old, free from target organ damage, and must have agreed to participate in the study after informed consent according to the Helsinki recommendations III. Patients with Diabetes Mellitus (Type 1 or Type 2) that have been treated with insulin, patients in gestational state and those with heart failure or chronic kidney disease were excluded. The medical history associated with physical examination, ophthalmoscopy, electrocardiogram, urine examination made it possible to exclude hypertensive patients with target organ damage. Finally, from 1917 hypertensive patients followed in the Lomo Medical Center during the period from 5 January 2007 to 5 January 2010, 171 were eligible for the study, but only 163 have given their informed consent to participate in this study.

Eligible participants were invited to attend the survey at Lomo Medical Center on specified dates. They were instructed and encouraged not to eat after 10:00 p.m. before the laboratory measurements. Alcohol, smoking and chewing gum were prohibited at the fasting period and during the test. Baseline overnight fasting blood was drawn between 7:00 and 9:00 a.m.

The following clinical information was obtained from a questionnaire ad hoc: demographic data (age, gender), risk behavior (excessive alcohol consumption, cigarette smoking), personal history (hypertension, diabetes mellitus).

For each patient, a trained nurse measured body weight $(\mathrm{kg})$, height $(\mathrm{cm})$, waist circumference $(\mathrm{cm})$, hip circumference $(\mathrm{cm})$ and blood pressure (mmHg). Body weight was measured using scale WaagenGmbh Co-Soenle, Murrhardt, German manufacturers. The patient was barefoot, lightly clad, standing motionless at the center of the weighing pan, upper limbs along the body; the body weight is evenly distributed on both feet. The measurement was recorded to the nearest milligram. Height was measured using a stadiometer wall, the patient being barefoot standing heels together, head positioned so that the line of sight is perpendicular to the body. Head, back, buttocks and heels were in contact with the vertical board of the toise. The participant took a deep breath and remained in this extended position while the cursor was brought into contact with the highest point of the head, pressing it to compress the hair. The measurement was recorded to the nearest millimeter. The body mass index (BMI) was calculated as weight (kg)/squared height (m). The waist circumference was measured; the participant was standing, with feet apart at about $25 \mathrm{~cm}$, using a tape put through the umbilicus and halfway between the grid rib and the iliac crest. The measurement was taken at the end of expiration and it was recorded to the nearest millimeter. The hip circumference was measured under the same conditions; the ribbon was put through the widest part of the basin. Sitting blood pressure (BP) was measured non-invasively on the left arm, using an automated oscillometric BP recorder OMRON M6 worn cuff at heart level, the patient being seated for 5 minutes. An average of three consecutive shots each separated by three minute interval was chosen.

\subsection{Laboratory Determinations}

For all analyses, a blood sample was taken between 7 am and 9 am at the cubital vein of the patient after an overnight fasting of 10 hours. All analyses were performed in the laboratory of Lomo Medical Center.

For the determination of serum uric acid level, total cholesterol, LDL-cholesterol, HDL-cholesterol and triglycerides, blood was collected in a dry tube. The serum collected was used for the analysis. The assay was performed by the standard colorimetric method. The reagents used were from the firm BIOLABO. Readings were measured by colorimetric spectrophotometer brand HELIOS Epsilon (USA). 
The dosage of CRP (C-reactive protein) was performed on serum by serological method using reagents CRPSlidex from the firm Bio-Mérieux (France).

The blood glucose test was performed on plasma oxalate by colorimetric method using standard reagents Biolabo. Reading was measured by HELIOS Epsilon spectrophotometer (USA).

The dosage of insulin was performed on EDTA plasma by ELISA. Reading the optical density was done on a string read from the firm HUMAREADER HUMAN (Germany).

The glycated hemoglobin was performed on plasma treated with EDTA by electrophoretic method. The equipment used for the measurement was HYRYS HYDRASIS from the firm SEBIA (France).

The serum creatinine was performed on serum by the method of simple colorimetric Jaffe. Reading was measured by colorimetric spectrophotometer (Spectrum 2100 brand, South Africa). The study was performed according to the guidelines of Helsinki Declaration. Informed consent was obtained from all patients and ethic committee approved data collection.

\subsection{Operational Definitions}

HTN was defined as a office systolic blood pressure (SBP) $\geq 140 \mathrm{mmHg}$ and/or a office diastolic blood pressure (DBP) $\geq 90 \mathrm{mmHg}$ and/or current use of antihypertensive drugs whatever the level of BP [6] [53] [54]. HTN was defined as essential only on the basis of medical history, physical examination and urine analysis; specific tests to rule out secondary causes of HTN were not performed. Diastolic HTN was defined as diastolic blood pressure $\geq$ $90 \mathrm{mmHg}$, irrespective of systolic pressure [55]. Homeostatic model assessment index for insulin resistance (HOMA-IR) was calculated by dividing the product of insulin (microunits per milliliter) and glucose (millimoles per liter) by 22.5 [55] and the IR was defined by the values of HOMA-IR score $\geq 2.5$ [56]. Creatinine clearance (CrCl) was calculated according to Cockroft-Gault equation [57]. A CCl $<60 \mathrm{ml} / \mathrm{min}$ was defined as chronic kidney disease (CKD) according to the National Kidney Foundation guidelines [58]. DM was defined as fasting glycaemia $\geq 7 \mathrm{mmol} / 1$ ( $\geq 126 \mathrm{mg} / \mathrm{dl}$ ) and/or 2 hour postprandial glucose test $\geq 11.1 \mathrm{mmol} / 1$ ( $\geq 200 \mathrm{mg} / \mathrm{dl})$ [59]. Participants who were aware of being diabetic had their medical history of DM confirmed by a record review conducted at Lomo Medical Center. Type 2 diabetes was defined according to the Expert Committee on the Diagnosis and Classification of Diabetes Mellitus [59]. Cigarette smoking was defined as a regular intake of tobacco smoke for at least 30 days prior to this study, regardless of the number of cigarettes. Excessive alcohol consumption has been defined by $>2$ glasses of beer/day or its equivalent for at least one year prior to this study [60]. AO was defined according to the NCEP ATP III (WC $>102 \mathrm{~cm}$ for males and $>88 \mathrm{~cm}$ for female), according to IDF (WC $>94 \mathrm{~cm}$ for males and $>80 \mathrm{~cm}$ for female) [48] and according to Kasiam et al. proposed AO-SSA (WC > $94 \mathrm{~cm}$ for both males and female [47]. The MetS was defined according to the NCEP ATP III [61], IDF [48] and SSA criteria. The SSA criteria are those of the IDF, in which the cutoff of AO is the one proposed by Kasiam et al. for SSA [47]. Dyslipidemia was defined by the presence of HDL cholesterol $<40 \mathrm{mg} / \mathrm{dl}$ in men and $<50 \mathrm{mg} / \mathrm{dl}$ in women and/or LDL cholesterol $\geq 130 \mathrm{mg} / \mathrm{dl}$ and/or total cholesterol $\geq 185 \mathrm{mg} / \mathrm{dl}$ and/or triglycerides $\geq 150 \mathrm{mg} / \mathrm{dl}$ [62]. Cardiometabolic risk factors considered in this study were age $>55$ years, Type 2 diabetes mellitus, hypertension, cigarette smoking, excessive alcohol intake, a pulse pressure $>60 \mathrm{mmHg}$, AO, dyslipidemia and MetS.

\subsection{Statistical Analyses}

The normal distribution of each variable was tested by Kolmogorov-Smirnov's test. Continuous variables were expressed as mean \pm standard deviation and qualitative variables were presented as proportions (percentage).

The Chi-square test and Student t-test were used to compare proportions and means between groups and subgroups respectively.

One-way analysis of variance (ANOVA) with post hoc Duncan tests was applied to compare the differences among the groups. Calculating the odds ratio (OR) and confidence intervals at $95 \%$, using the logistic regression analysis, was used to assess the relative contribution of each factor to the risk of high HOMA-IR. The probability value (p) less than 0.05 (5\%) was considered as the threshold of statistical significance. The kappa statistic was determined for agreement between the ATPIII, IDF and SSA defined AO and MetS with HOMA-IR. The three definitions of MetS and the three cut-off point of AO were compared with the results of HOMA-IR, and sensitivity, specificity, positive predictive value, negative predictive value were calculated. The statistical analysis was performed using SPSS, version 18, software (SPSS Inc., Chicago, IL, USA). 


\section{Results}

A total of 163 hypertensive patients were evaluated (64.4\% males, mean age: $57 \pm 11$ years) of whom 58 (35.6\%) were diabetic. A number of 62 (38.0\%), 58 (35.5\%), 13 (7.9\%) had MetS according to ATP III, IDF and SSA definition respectively. A number of 84 (51.5\%), 135 (82.8\%) and 124 (76.0\%) had AO according to ATP, IDF and SSA cutoff points respectively.

Demographic and clinical characteristics of the study population as a whole and stratified by the IR status are represented in Table 1. We found that the level of weight, WC, BMI and HOMA-IR was higher in IR patients.

Biological characteristics of the study population as a whole and stratified by the IR status are represented in Table 2. In which we notice that the level of LDL-C, TG and Uric acid are significantly elevated in the sub-group with IR.

Table 3 shows the rate of IR throughout the whole study population and in various subgroups of the population. IR was found in $79.1 \%$ of the study population. The prevalence of IR is higher in patients with AO defined according to Kasiam et al. proposed Sub-Saharan Africa Specific Cut-off point.

The importance of other cardiometabolic risk factors was emphasized in Table 4.

The univariate risk factors for IR were age $<55$ years, cigarette smoking, hyperuricemia, low HDL-C, elevated LDL-C, diastolic HTN, and HbA1c > 6.5\% (Table 5).

In multivariate analysis, the risk of IR was associated independently and significantly $(\mathrm{p}<0.05)$ by cigarette smoking, low-HDL-C, hyperuricemia, and diastolic HTN. This is shown in Table 6 and illustrated in the following equation:

$\mathrm{Y}=-1.404$ + 1.054 Cigarette Smoking + 0.872 low HDL-C + 0.983 hyperuricemia + 0.852 diastolic HTN.

Tables 7-12 summarize the sensitivities and specificities of ATP III, IDF and SSA criteria defined MetS and AO for IR in hypertensive patients. The sensitivity and specificity of MetS-ATP III criteria for IR in subjects with HTN were 42.6 and 79.4\% respectively. Using the MetS-IDF, the sensitivity was 35.6\% and the specificity was $64.7 \%$. The MetS-SSA provided $8.5 \%$ of specificity and $94.1 \%$ of sensitivity. Using the AO-ATP III, AO-IDF, AO-SSA, the sensitivity and specificity were 46.5 and $29.4 \%, 79.0$ and 2.9\%, 87.5 and 67.6\% respectively.

Table 1. Demographic and clinical characteristics of the study population as a whole and stratified by the IR status.

\begin{tabular}{|c|c|c|c|c|}
\hline Characteristic & $\begin{array}{l}\text { Whole group } \\
\qquad(\mathrm{n}=163)\end{array}$ & $\begin{array}{l}\text { Insulinresistant } \\
(\mathrm{n}=129)\end{array}$ & $\begin{array}{l}\text { Insulin sensitive } \\
\qquad(\mathrm{n}=34)\end{array}$ & $\mathrm{p}$ \\
\hline Age (years) & $57 \pm 11$ & $57.09 \pm 11.17$ & $57.86 \pm 13.38$ & 0.750 \\
\hline Gender (M/F) & $105 / 58$ & $82 / 47$ & 23/11 & 0.62 \\
\hline DHTN (years) & $4 \pm 3.2$ & $4.2 \pm 3.1$ & $4 \pm 1.5$ & 0.781 \\
\hline Diastolic HTN, n(\%) & $124(76.0)$ & 99 (76.7) & 25 (73.5) & 0.000 \\
\hline Body weight (kg) & $87 \pm 15$ & $90.55 \pm 14.80$ & $71.11 \pm 10.60$ & 0.001 \\
\hline Body height (cm) & $1.64 \pm 0.076$ & $1.64 \pm 7.83$ & $1.64 \pm 6.78$ & 0.989 \\
\hline Waistcircumference (cm) & $99.3 \pm 11.6$ & $102.36 \pm 9.66$ & $85.00 \pm 9.75$ & 0.000 \\
\hline BMI $\left(\mathrm{kg} / \mathrm{m}^{2}\right)$ & $32.37 \pm 6.14$ & $33.61 \pm 5.72$ & $26.43 \pm 4.43$ & 0.000 \\
\hline
\end{tabular}

$\mathrm{M} / \mathrm{F}=$ male/female; DHTN = Duration of Hypertension; BMI = Body mass index.

Table 2. Biological characteristics of the study population as a whole and stratified by the IR status.

\begin{tabular}{|c|c|c|c|c|}
\hline Characteristics & Study pop $(\mathrm{n}=163)$ & $\mathrm{IR}+(\mathrm{n}=129)$ & $\mathrm{IR}-(\mathrm{n}=34)$ & $\mathrm{p}$ \\
\hline Glucose (mg/dL) & $120 \pm 20$ & $125 \pm 15$ & $109 \pm 20$ & 0.08 \\
\hline HbA1C & $7.2 \pm 3.6$ & $8.6 \pm 2.5$ & $5.9 \pm 0.5$ & 0.02 \\
\hline $\mathrm{TC}(\mathrm{mg} / \mathrm{dL})$ & $212 \pm 11$ & $220 \pm 23$ & $196 \pm 41$ & 0.06 \\
\hline HDL-C, (mg/dL) & $56.4 \pm 12$ & $56 \pm 11$ & $59 \pm 13$ & 0.09 \\
\hline LDL-C (mg/dL) & $139.2 \pm 35$ & $142 \pm 21$ & $131 \pm 18$ & $<0.001$ \\
\hline Triglyceride (mg/dL) & $80.8 \pm 46$ & $128 \pm 32$ & $131 \pm 24$ & 0.04 \\
\hline Creatinine (mg/dL) & $1.2 \pm 0.60$ & $1.1 \pm 0.25$ & $0.97 \pm 0.33$ & 0.12 \\
\hline Creat cl (mL/min) & $90 \pm 20$ & $91.42 \pm 20$ & $95 \pm 12$ & 0.10 \\
\hline Uric acid (mg/dL) & $7 \pm 2.52$ & $8.3 \pm 2.1$ & $5.16 \pm 1.39$ & 0.002 \\
\hline
\end{tabular}


Table 3. Prevalence of IR in the whole study population and in various subgroups of the population.

\begin{tabular}{cc}
\hline & Prevalence of IR \% (n) \\
\hline Whole Population & $79.1(129)$ \\
ATP III-MetS & $88.7(55 / 62)$ \\
IDF-MetS & $79.3(46 / 58)$ \\
SSA-MetS & $84.6(11 / 13)$ \\
ATP III-AO & $71.4(60 / 84)$ \\
IDF-AO & $75.5(102 / 135)$ \\
SSA-AO & $91.1(113 / 124)$ \\
Diabetic patients & $60.3(35 / 58)$ \\
Non-diabetic and non-obese patients & $44.8(47 / 105)$ \\
\hline
\end{tabular}

Table 4. Frequency of other cardiometabolic risk factors.

\begin{tabular}{cc}
\hline Risk factor & Frequency n(\%) \\
Age $>55$ years & $143(87.7)$ \\
Cigarette smoking & $16(9.8)$ \\
Excessive alcoholintake & $32(19.6)$ \\
DT2 & $58(35.6)$ \\
AO: & \\
$\bullet \quad$ AO-ATP III & $84(51.5)$ \\
$\bullet \quad$ AO-IDF & $135(82.8)$ \\
$\bullet \quad$ AO-SSA & $124(76.1)$ \\
Total cholesterol $\geq 185 \mathrm{mg} / \mathrm{dl}$ & $87(53.3)$ \\
LDL-C $\geq 130 \mathrm{mg} / \mathrm{dl}$ & $50(30.6)$ \\
HDL-c $<40 \mathrm{mg} / \mathrm{dl}(\mathrm{M})$ ou $<50 \mathrm{mg} / \mathrm{dl}(\mathrm{F})$ & $80(49.0)$ \\
TG $\geq 150 \mathrm{mg} / \mathrm{dL}$ & $87(53.3)$ \\
$\bullet \quad$ MetS: & $62(38.0)$ \\
$\bullet \quad$ MetS-ATP III & $58(35.5)$ \\
$\bullet \quad$ MetS-SSA & $13(7.9)$ \\
\hline
\end{tabular}

\section{Discussion}

This is the first study in Democratic Republic of Congo to investigate the prevalence of IR and its determinants in hypertensive patients. This is also the first to evaluate the intrinsic and extrinsic characteristics of the AOSSA in particular and the characteristics of the other threshold defined AO and MetS in general in identifying IR in Congolese Black Hypertensive patients. The HOMA-IR served as a gold standard for IR, because of its reasonable linear correlation with glucose clamp and minimal model estimates of insulin sensitivity/resistance in several studies of distinct populations [63].

This study has demonstrated that IR is prevalent in Congolese Black Hypertensive Patients. Since the IR represents an important risk factor for the development of Type 2 diabetes, this high prevalence of IR can predict a worrisome trend for the burden of Type 2 diabetes in hypertensive patients. Unsurprisingly, the most important prevalence of IR has been found among obese patients and among those with MetS. The highest prevalence of IR has been found among hypertensive patients classified as obese according to the Kasiam et al. proposed cut-off point compared with those with AO or MetS according to other criteria. Contrary to what would suggest the pathophysiological reasoning, which puts the abdominal obesity on the center of the genesis of IR, an important proportion of insulin-resistant patients (44.8\%) were also found among hypertensive patients who were not obese or diabetic, i.e. without insulin resistance phenotype. This percentage is within the range (25\% - 50\%) reported in the literature (7). Indeed, many authors, following Ferrannini have demonstrated that HTN is associated with insulin resistance independent of obesity and glucose intolerance [64].

This study also showed that the prevalence of IR is higher among the younger population, suggesting an early 
Table 5. Risk factors for IR.

\begin{tabular}{cc}
\hline Independent variables & OR (IC 95\%) \\
& $(\%$ vs. \%) \\
p & $2.1(1.3-10)$ \\
Age (years) & 87.7 vs. 12.3 \\
$<55$ vs. $\geq 55$ & 0.04 \\
& $3.1(1.2-8.5)$ \\
Cigarette smoking & 9.8 vs. 90.2 \\
Yes vs. No & 0.03 \\
Hyperuricemia & $2.7(1.3-5.6)$ \\
Yes vs. No & 39.2 vs. 60.8 \\
& $<0.01$ \\
Low HDL-C (mg/dl) & $9.9(5-10.2)$ \\
Yes vs. No & 53.3 vs. 46.7 \\
Elevated LDL-C & 0.008 \\
Yes vs. No & $2.2(1.8-5.6)$ \\
& 37.4 vs. 62.6 \\
Diastolic Hypertension & 0.04 \\
Yes vs. No & $9.8(4.9-10)$ \\
Glycated Hemoglobin $>6.5 \%$ & 93.3 vs. 6.7 \\
Yes vs. No & 0.019 \\
& $3.3(1.7-10)$ \\
& 83.4 vs. 6.6 \\
& 0.014
\end{tabular}

Table 6. Independent determinants of IR in the study population.

\begin{tabular}{|c|c|c|c|c|}
\hline \multirow{2}{*}{ Independent variables } & \multicolumn{2}{|c|}{ Non-standardized test } & \multirow[t]{2}{*}{$\operatorname{Exp}(B)=$ OR (IC 95\%) } & \multirow{2}{*}{$\mathrm{p}$} \\
\hline & B & ES & & \\
\hline $\begin{array}{l}\text { Cigarette smoking } \\
\text { Yes vs. No }\end{array}$ & 1.054 & 0.552 & $3.1(1.2-8.5)$ & 0.049 \\
\hline $\begin{array}{l}\text { Low HDL-C } \\
\text { Yes vs. No }\end{array}$ & 0.872 & 0.406 & $2.4(1.1-5.3)$ & 0.032 \\
\hline $\begin{array}{l}\text { Hyperuricemia } \\
\text { Yes vs. No }\end{array}$ & 0.983 & 0.381 & $2.7(1.3-5.6)$ & $<0.0001$ \\
\hline $\begin{array}{l}\text { Diastolic HTN } \\
\text { Yes vs. No }\end{array}$ & 0.852 & 0.381 & $4.2(2.1-7.4)$ & $<0.0001$ \\
\hline Constant & -1.404 & 0.258 & & $<0.0001$ \\
\hline
\end{tabular}

Table 7. Comparison of ATP III defined MetS with HOMA-IR.

\begin{tabular}{|c|c|c|c|c|}
\hline & & \multicolumn{2}{|c|}{ HOMA-IR } & \multirow[b]{2}{*}{ Total } \\
\hline & & $>2.5$ & $\leq 2.5$ & \\
\hline \multirow{3}{*}{ ATP III-MetS } & Yes & 55 & 7 & 62 \\
\hline & No & 74 & 27 & 101 \\
\hline & Total & 129 & 34 & 163 \\
\hline
\end{tabular}

Sensitivity = 42.6\%; specificity = 79.4\%; positive predictive value $=88.7 \%$; negative predictive value $=26.7$; Kappa $=0.12$.

Table 8. Comparison of IDF defined MetS with HOMA-IR.

\begin{tabular}{|c|c|c|c|c|}
\hline & & \multicolumn{2}{|c|}{ HOMA-IR } & \multirow[b]{2}{*}{ Total } \\
\hline & & $>2.5$ & $\leq 2.5$ & \\
\hline \multirow{3}{*}{ IDF-MetS } & Yes & 46 & 12 & 58 \\
\hline & No & 83 & 22 & 105 \\
\hline & Total & 129 & 34 & 163 \\
\hline
\end{tabular}

Sensitivity $=35.6 \%$; specificity $=64.7 \%$; positive predictive value $=79.3 \%$; negative predictive value $=20.9$; Kappa $=0.02$. 
Table 9. Comparison of SSA-MetS with HOMA-IR.

\begin{tabular}{ccccc}
\hline & & HOMA-IR & & Total \\
\cline { 3 - 5 } & & $>2.5$ & 2.5 & 13 \\
\multirow{3}{*}{ SSA-MetS } & Yes & 11 & 32 & 150 \\
& No & 118 & 34 & 163 \\
\hline
\end{tabular}

Sensitivity $=8.5 \%$; specificity $=94.1 \%$; positive predictive value $=84.6 \%$; negative predictive value $=21.3 ;$ Kappa $=0.01$.

Table 10. Comparison of ATP cut-off point defined AO with HOMA-IR.

\begin{tabular}{|c|c|c|c|c|}
\hline & & \multicolumn{2}{|c|}{ HOMA-IR } & \multirow[b]{2}{*}{ Tota } \\
\hline & & $>2.5$ & $\leq 2.5$ & \\
\hline \multirow{3}{*}{ ATP-AO } & Yes & 60 & 24 & 84 \\
\hline & No & 69 & 10 & 79 \\
\hline & Total & 129 & 34 & 163 \\
\hline
\end{tabular}

Sensitivity = 46.5\%; specificity = 29.4\%; positive predictive value $=71.4 \%$; negative predictive value $=12.6$; Kappa $=0.16$.

Table 11. Comparison of IDF cut-off point defined AO with HOMA-IR.

\begin{tabular}{cccccc}
\hline & & & HOMA-IR & & \\
& & $>2.5$ & 32 & Total & 134 \\
\cline { 3 - 5 } IDF-AO & Yes & 102 & 1 & 29 \\
& No & 27 & 34 & 163 \\
\hline
\end{tabular}

Sensitivity $=79.0 \%$; specificity $=2.9 \%$; positive predictive value $=75.5 \%$; negative predictive value $=3.5$; Kappa $=0.18$.

Table 12. Comparison of SSA cut-off point defined AO with HOMA-IR.

\begin{tabular}{cccccc}
\hline & & & HOMA-IR & & \\
& & $>2.5$ & 11 & Total \\
\cline { 3 - 5 } SSA-AO & Yes & 113 & 124 & 39 \\
& No & 16 & 34 & 163 \\
\hline
\end{tabular}

Sensitivity = 87.5\%; specificity = 67.6\%; positive predictive value = 91.1\%; negative predictive value = 58.9; Kappa $=0.52$.

onset of insulin resistance in our study population. The same has been found by Kasiam et al. in a population based study [47]. Some genetic or environmental factors could explain this observation that has not been reported in Caucasians. This early IR is probably the underlying reason for the early onset of cardio metabolic complications that characterize HTN in black subjects. Prospective studies are needed to verify this hypothesis.

The determinants of IR found in this study are: cigarette smoking, low HDL-C, hyperuricemia and diastolic HTN. Cigarette smoking has the good reputation of modulating the appetite and thus to control the weight [65]. Indeed, smokers are, on average, skinnier than nonsmokers. New research reveals how nicotine, the active ingredient in cigarettes, works in the brain to suppress smokers' appetites. Thus, the harmful effects of tobacco which include oxidative stress, endothelial dysfunction and sympathetic stimulation that occur as a result of smoking are unknown by the general public. These three mechanisms lead to insulin resistance, and therefore, to cardio metabolic complications. Moreover, studies have shown that smoking actually decreases insulin sensitivity in proportion to the intensity of cigarette consumption. It has also been confirmed by clinical studies that smoking cessation is accompanied by a gradual return to normal insulin sensitivity.

Low plasma concentrations of HDL-C is recognized as one of the typical dyslipidemia of IR states [40], and is felt to play an important, although not exclusive role in the accelerated atherosclerotic cardiovascular disease [66] [67].

Hyperuricemia is a common finding in patients with insulin resistance and hypertension [40] [68] [69]. Hyperuricemia has been attributed to hyperinsulinemia in metabolic syndrome and to decreased uric acid excre- 
tion in kidney dysfunction [70] [71]. Uric acid has antioxidant properties, but at supranormal levels, uric acid loses his antioxidant properties and may become pro-oxidant [72] and plays a pathophysiological role in the development of IR and cardiovascular disease [72]-[74]. Oxidative stress would be the link between hyperuricemia and insulin resistance.

Ferrannini et al. found that Insulin sensitivity, as measured in euglycemic clamp studies performed with physiological insulin concentrations, showed similar associations with systolic and diastolic blood pressures, whereas fasting insulinemia was only related to diastolic blood pressure [64]. This would explain the link found in this study between diastolic blood pressure and IR, as the HOMA-IR is calculated using fasting insulinemia.

The pathophysiological importance of IR in the development of cardiometabolic complications is such that it is important to identify IR in hypertensive patients. Since conventional methods are not only technically difficult to implement but also very expensive, the use of substitutes should focus on markers that are both easy to use, inexpensive and effective in identifying insulin resistant patients. For the first criteria (ease of implementation and cost), the measurement of waist circumference is probably cheaper and easier to use since it simply need a tape. But this facility and this cost should not sacrifice diagnostic performance.

Our study demonstrated that the IDF defined MetS using the Kasiam et al. proposed AO-SSA provided the best specificity, whereas the AO-SSA provided the best sensitivity. The MetS and AO defined according to the criteria of ATP III have a statistically similar sensitivity.

When comparing the AO defined according to different cutoff, the best sensitivity is obtained with Kasiam et al. proposed AO-SSA, followed by AO-IDF and AO-ATP, whereas the best specificity is obtained with AO-SSA followed by AO-ATP III and AO-IDF. When comparing MetS definitions, the best sensitivity is obtained with NCEP ATP III criteria, followed by IDF and IDF-SSA, whereas the best specificity is obtained with IDF-SSA followed by NCEP ATP III and IDF.

Considering the different definitions of the metabolic syndrome and different definitions of abdominal obesity according to different thresholds, the best specificity was obtained with the MetS-SSA (94.1\%) but it did not provide a sensitive approach (sensitivity: 8.5\%) to identifying IR and showed a slight agreement (Kappa $=0.01$ ) with HOMA-IR. Abdominal obesity defined according to Kasiam et al. proposed Sub-Saharan Africa cutoff-point offers the highest sensitivity (87.5\%), with good specificity (67.6\%). The rate of agreement of the AO-SSA, although moderate (kappa $=0.52$ ), is the best of all (Including the MetS regardless of the definition and AO defined according to other thresholds). The cutoff point of $94 \mathrm{~cm}$ regardless of gender was proposed by Kasiam et al. for SSA, echoing the IDF recommendation who stressed the need to adopt different values of WC measurements to define AO in different ethnic groups. This cutoff-point was set from a broad clinical study which showed that the WC $\geq 94$-cm cut-off point ( $\geq 90^{\text {th }}$ percentile of WC) corresponded to body mass index $\geq 30 \mathrm{~kg} / \mathrm{m}^{2}\left(\geq 90^{\text {th }}\right.$ percentile of BMI) and body fat mass $\geq 24 \mathrm{~kg}\left(90^{\text {th }}\right.$ percentile of BFM). This simple measurement using a tape is sufficient to identify insulin-resistant hypertensive patients, by exempting them from additional expensive assays that are required for the diagnosis of the MetS. Indeed, health insurance does not exist in SSA and the poverty of African patients is such that in general, laboratory tests are not available.

Our findings should be interpreted in the light of certain limitations including the cross-sectional design, the small number of participants, the non-inclusion of antihypertensive and other treatment. All things considered, the Kasiam et al. proposed SSA cutoff-point defined AO is an easy and cost efficient to diagnose IR in Congolese Black Hypertensive Patients. A further study in larger population is required to confirm this finding.

\section{Conclusion}

IR is present in the majority of Congolese patients with essential HTN, fore-shadowing a worrisome trend for the burden of Type 2 diabetes in Congolese black hypertensive patients. This IR could be amplified by cigarette smoking, low-HDL-C, hyperuricemia, and diastolic HTN. The AO-SSA is an easy and cost efficient surrogate marker for IR in Congolese Black Hypertensive Patients. Further study in wider group is indicated to validate our findings.

\section{Acknowledgements}

The authors sincerely thank all patients who agreed to participate in this study. They also express their deep gratitude to all the staff at the Lomo Medical Clinic for their friendly cooperation in the realization of this study. 


\section{References}

[1] Giles, T.D. (2006) Assessment of Global Risk: A Foundation for a New, Better Definition of Hypertension. Journal of clinical Hypertension (Greenwich, Conn), 8, 5-14. http://dx.doi.org/10.1111/j.1524-6175.2006.05835.x

[2] Kearney, P.M., Whelton, M., Reynolds, K., Muntner, P., Whelton, P.K. and He, J. (2005) Global Burden of Hypertension: Analysis of Worldwide Data. Lancet, 9455, 217-223. http://dx.doi.org/10.1016/S0140-6736(05)17741-1

[3] Ezzati, M., Lopez, A.D., Rodgers, A., Vander Hoorn, S. and Murray, C.J. (2002) Selected Major Risk Factors and Global and Regional Burden of Disease. Lancet, 9343, 1347-1360. http://dx.doi.org/10.1016/S0140-6736(02)11403-6

[4] Jeppesen, J., Hein, H.O., Suadicani, P. and Gyntelberg, F. (2001) Low Triglycerides-High High-Density Lipoprotein Cholesterol and Risk of Ischemic Heart Disease. Archives of Internalmedicine, 3, 361-366. http://dx.doi.org/10.1001/archinte.161.3.361

[5] Mittal, B.V. and Singh, A.K. (2010) Hypertension in the Developing World: Challenges and Opportunities. American Journal of Kidney Diseases: The Official Journal of the National Kidney Foundation, 3, 590-598.

[6] James, P.A., Oparil, S., Carter, B.L., Cushman, W.C., Dennison-Himmelfarb, C., Handler, J., Lackland, D.T., LeFevre, M.L., MacKenzie, T.D., Ogedegbe, O., et al. (2014) Evidence-Based Guideline for the Management of High Blood Pressure in Adults: Report from the Panel Members Appointed to the Eighth Joint National Committee (JNC 8). JAMA: The Journal of the American Medical Association, 5, 507-520. http://dx.doi.org/10.1001/jama.2013.284427

[7] Kengne, A.P., Awah, P.K., Fezeu, L. and Mbanya, J.C. (2007) The Burden of High Blood Pressure and Related Risk Factors in Urban Sub-Saharan Africa: Evidences from Douala in Cameroon. Africanhealth Sciences, 1, 38-44.

[8] Kadiri, S. (2005) Tackling Cardiovascular Disease in Africa. BMJ (Clinical Research ed), 7519, 711-712.

[9] Akinkugbe, O.O. (1990) Epidemiology of Cardiovascular Disease in Developing Countries. Journal of Hypertension Supplement: Official Journal of the International Society of Hypertension, 7, S233-S238.

[10] Lang, T. (1994) The Entity of Arterial Hypertension in Black Subjects. Presse Medicale, 36, 1642-1645.

[11] Saunders, E. (2004) Managing Hypertension in African-American Patients. Journal of Clinical Hypertension, 6, 19-25. http://dx.doi.org/10.1111/j.1524-6175.2004.03564.x

[12] Fiscella, K. and Holt, K. (2008) Racial Disparity in Hypertension Control: Tallying the Death Toll. Annals of Family Medicine, 6, 497-502. http://dx.doi.org/10.1370/afm.873

[13] Perkovic, V., Huxley, R., Wu, Y., Prabhakaran, D. and MacMahon, S. (2007) The Burden of Blood Pressure-Related Disease: A Neglected Priority for Global Health. Hypertension, 50, 991-997. http://dx.doi.org/10.1161/HYPERTENSIONAHA.107.095497

[14] Longo-Mbenza, B., Ngoma, D.V., Nahimana, D., Mayuku, D.M., Fuele, S.M., Ekwanzala, F. and Beya, C. (2008) Screen Detection and the WHO Stepwise Approach to the Prevalence and Risk Factors of Arterial Hypertension in Kinshasa. European Journal of Cardiovascular Prevention and Rehabilitation: Official Journal of the European Society of Cardiology, Working Groups on Epidemiology \& Prevention and Cardiac Rehabilitation and Exercise Physiology, 15, 503-508. http://dx.doi.org/10.1097/HJR.0b013e3282f21640

[15] Bayauli, P.M., M’Buyamba-Kayamba, J.R., Lemogoum, D., Thijs, L., Dramaix, M., Fagard, R., Staessen, J.A., Degaute, J.P., Ditu, M.S. and M’Buyamba-Kabangu, J.R. (2014) Cardiovascular Risk Factors among the Inhabitants of an Urban Congolese Community: Results of the VITARAA Study. IJC Metabolic \& Endocrine, 4, 33-38. http://dx.doi.org/10.1016/j.ijcme.2014.07.003

[16] Bayauli, M.P., M’Buyamba-Kayamba, J.R., Lemogoum, D., Fagard, R., Degaute, J.P., Ditu, M.S., Lepira, B.F. and M’Buyamba-Kabangu, J.R. (2014) Prehypertension, Hypertension and Associated Cardiovascular Risk Factors among Adult Congolese Urban Dwellers: Results of the Vitaraa Study. World Journal of Cardiovascular Diseases, 4, 390-398. http://dx.doi.org/10.4236/wjcd.2014.48049

[17] Laakso, M. (1993) How Good a Marker Is Insulin Level for Insulin Resistance? American Journal of Epidemiology, 137, 959-965.

[18] Reaven, G.M. and Chen, Y.D. (1996) Insulin Resistance, Its Consequences, and Coronary Heart Disease. Must We Choose One Culprit? Circulation, 93, 1780-1783. http://dx.doi.org/10.1161/01.CIR.93.10.1780

[19] Bergman, R.N. (2002) Pathogenesis and Prediction of Diabetes Mellitus: Lessons from Integrative Physiology. The Mount Sinai Journal of Medicine, 69, 280-290.

[20] Edelson, G.W. and Sowers, J.R. (1993) Insulin Resistance in Hypertension: A Focused Review. The American Journal of the Medical Sciences, 306, 345-347. http://dx.doi.org/10.1097/00000441-199311000-00014

[21] Zavaroni, I., Mazza, S., Dall’Aglio, E., Gasparini, P., Passeri, M. and Reaven, G.M. (1992) Prevalence of Hyperinsulinaemia in Patients with High Blood Pressure. Journal of Internal Medicine, 231, 235-240.

http://dx.doi.org/10.1111/j.1365-2796.1992.tb00529.x 
[22] Berglund, G. and Andersson, O. (1981) Body Composition, Metabolic and Hormonal Characteristics in Unselected Male Hypertensives. International Journal of Obesity, 5, 143-150.

[23] Ferrannini, E., Natali, A., Capaldo, B., Lehtovirta, M., Jacob, S. and Yki-Jarvinen, H. (1997) Insulin Resistance, Hyperinsulinemia, and Blood Pressure: Role of Age and Obesity. Hypertension, 30, 1144-1149. http://dx.doi.org/10.1161/01.HYP.30.5.1144

[24] Zhou, M.S., Schulman, I.H. and Zeng, Q. (2012) Link between the Renin-Angiotensin System and Insulin Resistance: Implications for Cardiovascular Disease. Vascular Medicine, 17, 330-341. http://dx.doi.org/10.1177/1358863X12450094

[25] Lakka, H.M., Laaksonen, D.E., Lakka, T.A., Niskanen, L.K., Kumpusalo, E., Tuomilehto, J. and Salonen, J.T. (2002) The Metabolic Syndrome and Total and Cardiovascular Disease Mortality in Middle-Aged Men. JAMA: The Journal of the American Medical Association, 288, 2709-2716. http://dx.doi.org/10.1001/jama.288.21.2709

[26] Isomaa, B., Almgren, P., Tuomi, T., Forsen, B., Lahti, K., Nissen, M., Taskinen, M.R. and Groop, L. (2001) Cardiovascular Morbidity and Mortality Associated with the Metabolic Syndrome. Diabetes Care, 24, 683-689. http://dx.doi.org/10.2337/diacare.24.4.683

[27] McFarlane, S.I., Banerji, M. and Sowers, J.R. (2001) Insulin Resistance and Cardiovascular Disease. The Journal of Clinical Endocrinology and Metabolism, 2, 713-718.

[28] Pyorala, K., Savolainen, E., Lehtovirta, E., Punsar, S. and Siltanen, P. (1979) Glucose Tolerance and Coronary Heart Disease: Helsinki Policemen Study. Journal of Chronic Diseases, 32, 729-745. http://dx.doi.org/10.1016/0021-9681(79)90052-3

[29] Ducimetiere, P., Eschwege, E., Papoz, L., Richard, J.L., Claude, J.R. and Rosselin, G. (1980) Relationship of Plasma Insulin Levels to the Incidence of Myocardial Infarction and Coronary Heart Disease Mortality in a Middle-Aged Population. Diabetologia, 19, 205-210. http://dx.doi.org/10.1007/BF00275270

[30] Despres, J.P., Lamarche, B., Mauriege, P., Cantin, B., Dagenais, G.R., Moorjani, S. and Lupien, P.J. (1996) Hyperinsulinemia as an Independent Risk Factor for Ischemic Heart Disease. The New England Journal of Medicine, 334, 952958. http://dx.doi.org/10.1056/NEJM199604113341504

[31] Yip, J., Facchini, F.S. and Reaven, G.M. (1998) Resistance to Insulin-Mediated Glucose Disposal as a Predictor of Cardiovascular Disease. The Journal of Clinical Endocrinology and Metabolism, 83, 2773-2776. http://dx.doi.org/10.1210/jcem.83.8.5005

[32] Zavaroni, I., Bonini, L., Gasparini, P., Barilli, A.L., Zuccarelli, A., Dall’Aglio, E., Delsignore, R. and Reaven, G.M. (1999) Hyperinsulinemia in a Normal Population as a Predictor of Non-Insulin-Dependent Diabetes Mellitus, Hypertension, and Coronary Heart Disease: The Barilla Factory Revisited. Metabolism: Clinical and Experimental, 48, 989-994. http://dx.doi.org/10.1016/S0026-0495(99)90195-6

[33] Facchini, F.S., Hua, N., Abbasi, F. and Reaven, G.M. (2001) Insulin Resistance as a Predictor of Age-Related Diseases. The Journal of Clinical Endocrinology and Metabolism, 86, 3574-3578. http://dx.doi.org/10.1210/jcem.86.8.7763

[34] Kraemer, F.B. and Ginsberg, H.N. (2014) Gerald M. Reaven, MD: Demonstration of the Central Role of Insulin Resistance in Type 2 Diabetes and Cardiovascular Disease. Diabetes Care, 37, 1178-1181. http://dx.doi.org/10.2337/dc13-2668

[35] Sowers, J.R., Standley, P.R., Ram, J.L., Jacober, S., Simpson, L. and Rose, K. (1993) Hyperinsulinemia, Insulin Resistance, and Hyperglycemia: Contributing Factors in the Pathogenesis of Hypertension and Atherosclerosis. American Journal of Hypertension, 6, 260s-270s.

[36] Kidambi, S., Kotchen, J.M., Krishnaswami, S., Grim, C.E. and Kotchen, T.A. (2011) Cardiovascular Correlates of Insulin Resistance in Normotensive and Hypertensive African Americans. Metabolism: Clinical and Experimental, 60, 835-842. http://dx.doi.org/10.1016/j.metabol.2010.07.036

[37] Reaven, G.M. (2003) Insulin Resistance/Compensatory Hyperinsulinemia, Essential Hypertension, and Cardiovascular Disease. The Journal of Clinical Endocrinology and Metabolism, 88, 2399-2403. http://dx.doi.org/10.1210/jc.2003-030087

[38] Jeppesen, J., Hein, H.O., Suadicani, P. and Gyntelberg, F. (2000) High Triglycerides and Low HDL Cholesterol and Blood Pressure and Risk of Ischemic Heart Disease. Hypertension, 36, 226-232. http://dx.doi.org/10.1161/01.HYP.36.2.226

[39] Abbasi, F., Feldman, D., Caulfield, M.P., Hantash, F.M. and Reaven, G.M. (2014) Relationship among 25-Hydroxyvitamin D Concentrations, Insulin Action, and Cardiovascular Disease Risk in Patients with Essential Hypertension. American Journal of Hypertension, 19, pii: hpu136.

[40] Bonora, E., Capaldo, B., Perin, P.C., Del Prato, S., De Mattia, G., Frittitta, L., Frontoni, S., Leonetti, F., Luzi, L., Marchesini, G., et al. (2008) Hyperinsulinemia and Insulin Resistance Are Independently Associated with Plasma Lipids, Uric Acid and Blood Pressure in Non-Diabetic Subjects. The GISIR Database. Nutrition, Metabolism, and Cardio- 
vascular Diseases, 18, 624-631. http://dx.doi.org/10.1016/j.numecd.2007.05.002

[41] Scheen, A.J., Paquot, N., Castillo, M.J. and Lefebvre, P.J. (1994) How to Measure Insulin Action in Vivo. Diabetes/ Metabolism Reviews, 10, 151-188. http://dx.doi.org/10.1002/dmr.5610100206

[42] Singh, B. and Saxena, A. (2010) Surrogate Markers of Insulin Resistance: A Review. World Journal of Diabetes, 1, 36-47. http://dx.doi.org/10.4239/wjd.v1.i2.36

[43] Hwu, C.M., Hsiao, C.F., Grove, J., Hung, Y.J., Chuang, L.M., Chen, Y.T., Curb, J.D., Chen, Y.D., Rodriguez, B. and Ho, L.T. (2007) Surrogate Estimates of Insulin Sensitivity in Subjects with Hypertension. Journal of Human Hypertension, 21, 246-252.

[44] Karter, A.J., Mayer-Davis, E.J., Selby, J.V., D’Agostino Jr., R.B., Haffner, S.M., Sholinsky, P., Bergman, R., Saad, M.F. and Hamman, R.F. (1996) Insulin Sensitivity and Abdominal Obesity in African-American, Hispanic, and NonHispanic White Men and Women. The Insulin Resistance and Atherosclerosis Study. Diabetes, 45, 1547-1555. http://dx.doi.org/10.2337/diab.45.11.1547

[45] Grundy, S.M. (2006) Metabolic Syndrome: Connecting and Reconciling Cardiovascular and Diabetes Worlds. Journal of the American College of Cardiology, 47, 1093-1100. http://dx.doi.org/10.1016/j.jacc.2005.11.046

[46] Cheal, K.L., Abbasi, F., Lamendola, C., McLaughlin, T., Reaven, G.M. and Ford, E.S. (2004) Relationship to Insulin Resistance of the Adult Treatment Panel III Diagnostic Criteria for Identification of the Metabolic Syndrome. Diabetes, 53, 1195-1200. http://dx.doi.org/10.2337/diabetes.53.5.1195

[47] Kasiam Lasi On’kin, J.B., Longo-Mbenza, B., Nge Okwe, A. and Kangola Kabangu, N. (2007) Survey of Abdominal Obesities in an Adult Urban Population of Kinshasa, Democratic Republic of Congo. Cardiovascular Journal of Africa, 18, 300-307.

[48] Alberti, K.G., Zimmet, P. and Shaw, J. (2005) The Metabolic Syndrome: A New Worldwide Definition. Lancet, 366, 1059-1062. http://dx.doi.org/10.1016/S0140-6736(05)67402-8

[49] Delavari, A., Forouzanfar, M.H., Alikhani, S., Sharifian, A. and Kelishadi, R. (2009) First Nationwide Study of the Prevalence of the Metabolic Syndrome and Optimal Cutoff Points of Waist Circumference in the Middle East: The National Survey of Risk Factors for Noncommunicable Diseases of Iran. Diabetes Care, 32, 1092-1097. http://dx.doi.org/10.2337/dc08-1800

[50] Mohsen Ibrahim, M., Elamragy, A.A., Girgis, H. and Nour, M.A. (2011) Cut off Values of Waist Circumference \& Associated Cardiovascular Risk in Egyptians. BMC Cardiovascular Disorders, 11, 53-60. http://dx.doi.org/10.1186/1471-2261-11-53

[51] Bener, A., Yousafzai, M.T., Darwish, S., Al-Hamaq, A.O., Nasralla, E.A. and Abdul-Ghani, M. (2013) Obesity Index that Better Predict Metabolic Syndrome: Body Mass Index, Waist Circumference, Waist Hip Ratio, or Waist Height Ratio. Journal of Obesity, 2013, Article ID: 269038. http://dx.doi.org/10.1155/2013/269038

[52] Longo-Mbenza, B., Kasiam Lasi On’kin, J.B., Nge Okwe, A. and Kangola Kabangu, N. (2011) The Metabolic Syndrome in a Congolese Population and Its Implications for Metabolic Syndrome Definitions. Diabetes \& Metabolic Syndrome, 5, 17-24. http://dx.doi.org/10.1016/j.dsx.2010.05.009

[53] Ferdinand, K.C. (2010) Management of High Blood Pressure in African Americans and the 2010 ISHIB Consensus Statement: Meeting an Unmet Need. Journal of Clinical Hypertension, 12, 237-239. http://dx.doi.org/10.1111/j.1751-7176.2010.00272.x

[54] Mancia, G., Fagard, R., Narkiewicz, K., Redon, J., Zanchetti, A., Bohm, M., Christiaens, T., Cifkova, R., De Backer, G., Dominiczak, A., et al. (2013) 2013 ESH/ESC Practice Guidelines for the Management of Arterial Hypertension. European Heart Journal, 34, 2159-2219. http://dx.doi.org/10.1093/eurheartj/eht151

[55] Fagard, R.H. and Van den Enden, M. (2003) Treatment and Blood Pressure Control in Isolated Systolic Hypertension vs Diastolic Hypertension in Primary Care. Journal of Human Hypertension, 17, 681-687. http://dx.doi.org/10.1038/sj.jhh.1001598

[56] Longo-Mbenza, B., Nkongo Mvindu, H., Kasiam On’kin, J.B., Bikuku, N., Kianu Phanzu, B., Nge Okwe, A. and Kabangu, N. (2011) The Deleterious Effects of Physical Inactivity on Elements of Insulin Resistance and Metabolic Syndrome in Central Africans at High Cardiovascular Risk. Diabetes \& Metabolic Syndrome, 5, 1-6. http://dx.doi.org/10.1016/j.dsx.2010.05.001

[57] Cockcroft, D.W. and Gault, M.H. (1976) Prediction of Creatinine Clearance from Serum Creatinine. Nephron, 16, 3141. http://dx.doi.org/10.1159/000180580

[58] Hogg, R.J., Furth, S., Lemley, K.V., Portman, R., Schwartz, G.J., Coresh, J., Balk, E., Lau, J., Levin, A., Kausz, A.T., et al. (2003) National Kidney Foundation's Kidney Disease Outcomes Quality Initiative Clinical Practice Guidelines for Chronic Kidney Disease in Children and Adolescents: Evaluation, Classification, and Stratification. Pediatrics, 111, 1416-1421. http://dx.doi.org/10.1542/peds.111.6.1416

[59] Members of the Expert Committee on the Diagnosis and Classification of Diabetes Mellitus (2003) Report of the Ex- 
pert Committee on the Diagnosis and Classification of Diabetes Mellitus. Diabetes Care, 25, S5-S20.

[60] Peretti-Watel, P., Constance, J., Seror, V. and Beck, F. (2009) Cigarettes and Social Differentiation in France: Is Tobacco Use Increasingly Concentrated among the Poor? Addiction, 104, 1718-1728. http://dx.doi.org/10.1111/j.1360-0443.2009.02682.x

[61] Cleeman, J.I., et al. (2001) Executive Summary of the Third Report of the National Cholesterol Education Program (NCEP) Expert Panel on Detection, Evaluation, and Treatment of High Blood Cholesterol in Adults (Adult Treatment Panel III). JAMA: The Journal of the American Medical Association, 285, 2486-2497.

[62] Erdine, S., Ari, O., Zanchetti, A., Cifkova, R., Fagard, R., Kjeldsen, S., Mancia, G., Poulter, N., Rahn, K.H., Rodicio, J.L., et al. (2006) ESH-ESC Guidelines for the Management of Hypertension. Herz, 4, 331-338.

[63] Muniyappa, R., Lee, S., Chen, H. and Quon, M.J. (2008) Current Approaches for Assessing Insulin Sensitivity and Resistance in Vivo: Advantages, Limitations, and Appropriate Usage. American Journal of Physiology Endocrinology and Metabolism, 294, E15-E26.

[64] Ferrannini, E., Buzzigoli, G., Bonadonna, R., Giorico, M.A., Oleggini, M., Graziadei, L., Pedrinelli, R., Brandi, L. and Bevilacqua, S. (1987) Insulin Resistance in Essential Hypertension. The New England Journal of Medicine, 317, 350357. http://dx.doi.org/10.1056/NEJM198708063170605

[65] Williamson, D.F., Madans, J., Anda, R.F., Kleinman, J.C., Giovino, G.A. and Byers, T. (1991) Smoking Cessation and Severity of Weight Gain in a National Cohort. The New England Journal of Medicine, 324, 739-745. http://dx.doi.org/10.1056/NEJM199103143241106

[66] Rashid, S., Watanabe, T., Sakaue, T. and Lewis, G.F. (2003) Mechanisms of HDL Lowering in Insulin Resistant, Hypertriglyceridemic States: The Combined Effect of HDL Triglyceride Enrichment and Elevated Hepatic Lipase Activity. Clinical Biochemistry, 36, 421-429. http://dx.doi.org/10.1016/S0009-9120(03)00078-X

[67] Borggreve, S.E., De Vries, R. and Dullaart, R.P. (2003) Alterations in High-Density Lipoprotein Metabolism and Reverse Cholesterol Transport in Insulin Resistance and Type 2 Diabetes Mellitus: Role of Lipolytic Enzymes, Lecithin: Cholesterol Acyltransferase and Lipid Transfer Proteins. European Journal of Clinical Investigation, 33, 1051-1069. http://dx.doi.org/10.1111/j.1365-2362.2003.01263.x

[68] Yoo, T.W., Sung, K.C., Shin, H.S., Kim, B.J., Kim, B.S., Kang, J.H., Lee, M.H., Park, J.R., Kim, H., Rhee, E.J., et al. (2005) Relationship between Serum Uric Acid Concentration and Insulin Resistance and Metabolic Syndrome. Circulation Journal: Official Journal of the Japanese Circulation Society, 69, 928-933. http://dx.doi.org/10.1253/circj.69.928

[69] Wang, M., Zhao, D., Li, G.W., Wang, W., Liu, J., Liu, J., Liu, S., Qin, L.P. and Zhou, G.H. (2007) Correlation between Serum Uric Acid and Insulin Resistance. Zhonghua Yixue Zazhi, 46, 3260-3263.

[70] Salehidoost, R., Aminorroaya, A., Zare, M. and Amini, M. (2012) Is Uric Acid an Indicator of Metabolic Syndrome in the First-Degree Relatives of Patients with Type 2 Diabetes? Journal of Research in Medical Sciences: The Official Journal of Isfahan University of Medical Sciences, 17, 1005-1010.

[71] Osgood, K., Krakoff, J. and Thearle, M. (2013) Serum Uric Acid Predicts Both Current and Future Components of the Metabolic Syndrome. Metabolic Syndrome and Related Disorders, 11, 157-162. http://dx.doi.org/10.1089/met.2012.0151

[72] Lippi, G., Montagnana, M., Franchini, M., Favaloro, E.J. and Targher, G. (2008) The Paradoxical Relationship between Serum Uric Acid and Cardiovascular Disease. Clinica Chimica Acta, Clinica Chimica Acta, 392, 1-7. http://dx.doi.org/10.1016/j.cca.2008.02.024

[73] Alderman, M. and Aiyer, K.J. (2004) Uric Acid: Role in Cardiovascular Disease and Effects of Losartan. Current Medical Research and Opinion, 20, 369-379. http://dx.doi.org/10.1185/030079904125002982

[74] Soltani, Z., Rasheed, K., Kapusta, D.R. and Reisin, E. (2013) Potential Role of Uric Acid in Metabolic Syndrome, Hypertension, Kidney Injury, and Cardiovascular Diseases: Is It Time for Reappraisal? Current Hypertension Reports, 15, 175-181. http://dx.doi.org/10.1007/s11906-013-0344-5 
Scientific Research Publishing (SCIRP) is one of the largest Open Access journal publishers. It is currently publishing more than 200 open access, online, peer-reviewed journals covering a wide range of academic disciplines. SCIRP serves the worldwide academic communities and contributes to the progress and application of science with its publication.

Other selected journals from SCIRP are listed as below. Submit your manuscript to us via either submit@scirp.org or Online Submission Portal.
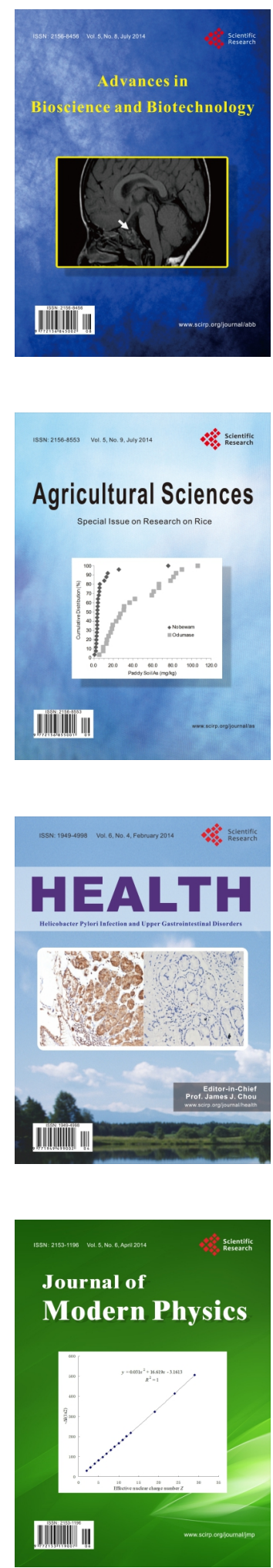
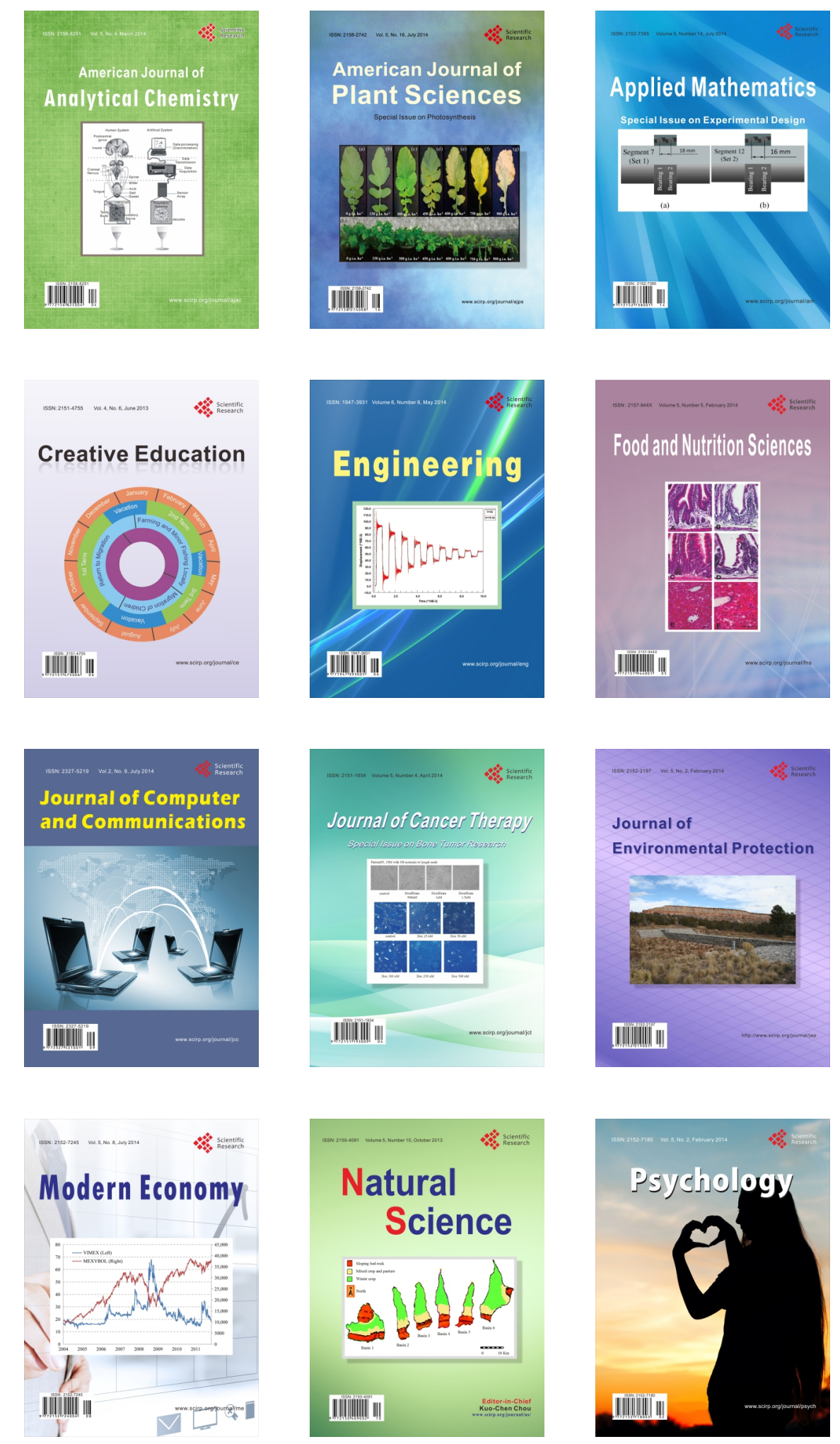